Original Research Article

\title{
Preclinical HbA1c level studies of makaradhwaja and siddha makaradhwaja after chronic administration to male Sprague-Dawley rats
}

\author{
Arjyabrata Sarker', Kushal Biswas ${ }^{2 *}$, Manjurul I. Chowdhury ${ }^{3}$, Farzana Khan ${ }^{2}$, \\ Taposhi Sultana ${ }^{2}$, Farjana Afrin ${ }^{4}$, Md. Afaz Uddin ${ }^{1}$, Md. Al Foyjul Islam ${ }^{1}$, M. S. K. Choudhuri ${ }^{1}$
}

${ }^{1}$ Department of Pharmacy, Jahangirnagar University, Savar, Dhaka 1342, Bangladesh ${ }^{2}$ Department of Pharmacy, East West University, Dhaka 1212, Bangladesh

${ }^{3}$ Global Centre for

Environmental Remediation,

The University of Newcastle, Callaghan, NSW 2308, Australia

${ }^{4}$ Department of Pharmacy,

Noakhali Science and

Technology University,

Noakhali 3814, Bangladesh

Received: 20 March 2017

Accepted: 22 April 2017

*Correspondence to:

Kushal Biswas,

Email: kushal71@outlook.com

Copyright: () the author(s), publisher and licensee Medip Academy. This is an openaccess article distributed under the terms of the Creative Commons Attribution NonCommercial License, which permits unrestricted noncommercial use, distribution, and reproduction in any medium, provided the original work is properly cited.

\begin{abstract}
Background: Makaradhwaja (MD) and Siddha Makaradhwaja (SMD) are Ayurvedic preparations used as traditional medicines for different clinical indications in the rural population. Principle purpose of using MD is controlling hypotension and while SMD is useful in peripheral circulatory failure treatment. In this study we evaluate the influence of these preparations on $\mathrm{HbAlc}(\%)$ level.

Methods: To find out the average plasma glucose concentration over prolonged period of time, MD and SMD were administered chronically to the male Sprague-Dawley rats at a dose of $40 \mathrm{mg} / \mathrm{kg}$. After 28 days of chronic administration of MD and SMD the following changes were noted and Glycated Hemoglobin (HbA1c) level was determined.

Results: The results of the study of in vitro quantitative determination of rat HbA1c concentrations in serum studies, MD demonstrated a negligible $(0.61 \%)$ decrease in the HbA1c level of the blood of the male rat $(p=0.902)$. Whereas SMD demonstrated a negligible $(1.83 \%)$ increase in the HbA1c level of the blood of the male rat $(\mathrm{p}=0.782)$.

Conclusions: Between these preparation MD slightly decreases HbAlc level of the blood of the male rat, whereas SMD found in increasing HbA1c level of the blood of the male rat.
\end{abstract}

Keywords: Diabetes mellitus, HbA1c, Makaradhwaja, Siddha Makaradhwaja

\section{INTRODUCTION}

The countries of Indian subcontinent are the mines of traditional medicines and medicinal plants. Among many of the lifesaving or disease curing preparations Makardhwaja (MD) and Siddha Makardhwaja (SMD) are the two names which are used in enormous purposes. These are mineral containing Ayurvedic traditional formulation. $^{1,2}$ MD is mainly prepared with purified mercury (Suddha Parad), purified sulphur (Suddha Gandhak) and gold (Swarna) which processed in Aloe Vera juice and other herbs in almost same proportion. 
Only difference between the formulation of MD and SMD is in the proportion of gold, where SMD lacks of it. These preparations are well known for their efficacy and safety in the treatment of neurological disorders, rheumatoid arthritis, tuberculosis, bradycardia, pneumonia and longevity of life. ${ }^{3,4}$ MD has been used for so many years for strengthening heart, as an anti-aging and aphrodisiac treatment, to relieve fever, dyspepsia and to improve immunity. ${ }^{5}$ However, SMD possesses exception for rejuvenation and convalescent therapy. ${ }^{6}$

Diabetes mellitus is a group of metabolic diseases that results from the defects of insulin secretion from $\beta$ - cells of Islets of Langerhans of pancreas, insulin action or may be both and characterized by constant hyperglycemia. ${ }^{7}$ Blood sugar levels can vary from one day to the next depending on food intake and activity levels. Hemoglobin A1C is a form of hemoglobin that is bound by glucose and is often referred to as glycated hemoglobin. ${ }^{8,9}$ Measurement of hemoglobin A1c (HbA1c) level is a combined measure of circulating glucose levels in individuals over time period (around 120 days). The higher glucose level in the plasma indicates that glucose level inside the red blood cell is high. That is more hemoglobin A1c is bound by the glucose. ${ }^{10-14}$ Therefore measuring the glycated hemoglobin level in the blood, the state of hyperglycemia as well as diabetes mellitus can be examined. That's been made the HbA1c as an ideal character for the determination. Beside these, $\mathrm{HbA1c}$ is an important tool for measuring some other possibilities, such as, detecting diseases of cardiovascular system, immunity and dyslipidemia. ${ }^{15-17}$

As MD and SMD are well known herbo-mineral preparation for several sign and symptoms, this research has been conducted to study the HbA1c level in male Sprague Dawley rats after chronic administration of this two Ayurvedic drugs. The aim of this study is to find out the relation between intake of those preparations (Makardhwaja and Siddha Makardhwaja) and its impact on HbA1c level.

\section{METHODS}

\section{Drugs, chemicals and reagents}

For this study, Makaradhwaja (MD) and Siddha Makaradhwaja (SMD) were collected from Sri Kundeswari Aushadhalaya Limited, Chittagong. All other reagents, assay kits and chemicals used in this work were purchased from Human GmbH, Wiesbaden, Germany.

\section{Experimental animals}

Eight-week old male Sprague-Dawley rats bred and maintained at the animal house of the Department of Pharmacy, Jahangirnagar University, which were used in this toxicological experiment. These animals were apparently healthy and weighed $50-70 \mathrm{~g}$. The animals were housed in a well-ventilated clean experimental animal house under constant environmental and adequate nutritional conditions throughout the period of the experiment. They were fed with rat chow prepared according to the formula developed by Bangladesh Council of Scientific and Industrial Research (BCSIR). Water was provided ad libitum and the animals were maintained at 12 hours day and 12 hours night cycle. All experiments on rats were carried out in absolute compliance with the ethical guide for care and use of laboratory animals approved by Ethical Review Committee, Faculty of Life Sciences, Department of Pharmacy, Jahangirnagar University.

\section{Specimen collection}

For the experiment, the liquid was administered at an oral dose of $40 \mathrm{mg} / \mathrm{kg}$ of the body weight by oral route, without affecting the total fluid volume in animal. Ketamine was administered intra-peritoneally $(500 \mathrm{mg} / \mathrm{kg}$ i.p.) as anesthetic agent.

\section{HbAlc assay}

HbA1c Assay consists of two separate concentration measurements, the glycated hemoglobin (HbA1c) and the total hemoglobin (THb). The two concentrations were used to determine the percent HbAlc or hemoglobin fraction. The individual concentration values of $\mathrm{HbA} 1 \mathrm{c}$ and $\mathrm{THb}$ generated by the assay were used for calculating the percent HbA1c. The whole blood specimen was first pre-treated with the MULTIGENT Hemoglobin Denaturant. The erythrocytes were lysed and the hemoglobin was degraded by the proteolytic enzyme, pepsin, to form a hemolysate. Both the THb and the HbA1c concentrations were determined from the same hemolysate. The concentration of total hemoglobin was determined calorimetrically and was based on the method described by Zander et al. ${ }^{18}$ The concentration of HbA1c was measured immune-turbidimetrically using a microparticle agglutination inhibition method. ${ }^{19}$ The individual concentration measurements of $\mathrm{THb}$ and HbA1c performed automatically by the ARCHITECT Systems and the AEROSET System and can be measured in $\mathrm{g} / \mathrm{dL}$ or $\mathrm{mmol} / \mathrm{L}$. The calculation of the percent $\mathrm{HbA} 1 \mathrm{c}$ was generated using the following equation:

$$
\begin{gathered}
\left(\frac{\operatorname{HbA} 1 \mathrm{c}\left(\frac{\mathrm{g}}{\mathrm{dL}}\right)}{\mathrm{THb}\left(\frac{\mathrm{g}}{\mathrm{dL}}\right)} \times 100\right)-3+\left(0.2 \times \mathrm{THb}\left(\frac{\mathrm{g}}{\mathrm{dL}}\right)\right) \\
=\% \operatorname{HbA} 1 \mathrm{c}
\end{gathered}
$$

\section{Statistical analysis}

The group data are expressed as Mean \pm SEM (Standard Error of the Mean). Independent sample ' $t$ ' tests were done for statistical significance analysis. SPSS (Statistical Package for Social Science) for WINDOWS (ver. 16.0) was applied for the analysis of data. Differences between 
groups were considered significant at $\mathrm{p}<0.05^{*}, 0.01^{* *}$ and $0.001 * * *$.

\section{RESULTS}

The HbA1c assay is used for the quantitative in vitro measurement of percent $\mathrm{HbA} 1 \mathrm{c}$ (HbA1c fraction) in whole blood. To find out the average plasma glucose concentration over prolonged period of time, Ayurvedic medicinal preparations MD and SMD were administered chronically to the male Sprague-Dawley rats at a dose of $40 \mathrm{mg} / \mathrm{kg}$. After 28days of chronic administration of MD and SMD the following changes were noted. In this experiment HbA1c level was determined. MD demonstrated a negligible $(0.61 \%)$ decrease in the HbA1c level of the blood of the male rat, which was statistically not at all significant $(\mathrm{p}=0.902)$. Whereas SMD demonstrated a negligible $(1.83 \%)$ increase in the HbA1c level of the blood of the male rat, which was statistically not at all significant $(\mathrm{p}=0.782)$.

Table 1: HbA1c (\%) value of control, MD and SMD.

\begin{tabular}{|c|c|c|c|}
\hline Parameters & Control (Mean \pm SEM) & MD $($ Mean \pm SEM $)$ & SMD (Mean \pm SEM) \\
\hline HbA1c (\%) & \multirow{3}{*}{$2.05000 \pm 0.07315$} & $2.03750 \pm 0.06797$ & $2.0875 \pm 0.11090$ \\
\hline $\mathrm{t} / \mathrm{p}$ & & $0.125 / 0.920$ & $-0.282 / 0.782$ \\
\hline Overall output & & $\begin{array}{l}\downarrow \text { Decrease } \\
0.609756 \%\end{array}$ & $\begin{array}{l}\uparrow \text { Increase } \\
1.82927 \%\end{array}$ \\
\hline
\end{tabular}

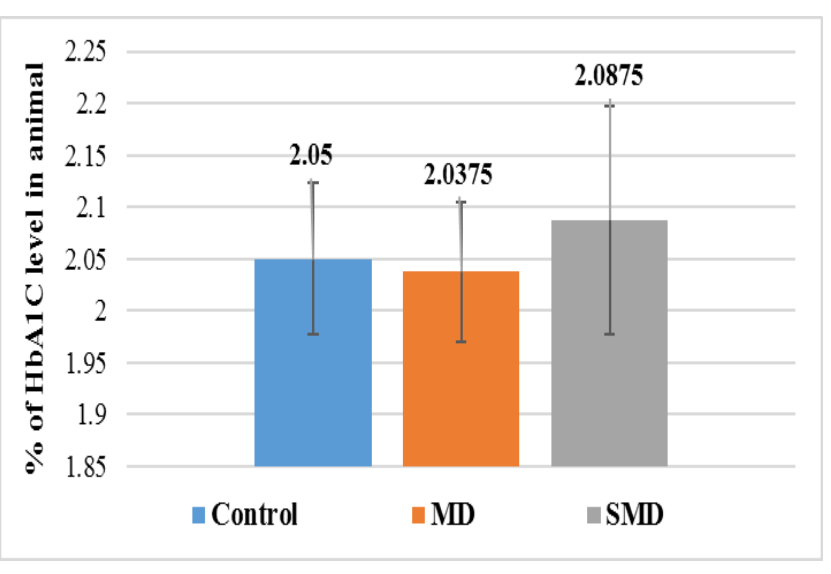

Figure 1: Effect of MD and SMD on HbA1c in male rats.

\section{DISCUSSION}

Makaradhwaja (MD) and Siddha Makaradhwaja (SMD) are Ayurvedic preparations used as traditional medicines for different clinical indications in the rural population. ${ }^{20-22}$ Makaradhwaja is used in hypotension and Siddha Makaradhwaja is used in peripheral circulatory failure. The HbAlc assay is intended to aid in the monitoring of long-term blood glucose control of the marketed Ayurvedic medicinal preparation. In this experiment, we found different $\mathrm{HbA} 1 \mathrm{c}$ level after treating the lab animals with those preparations. MD demonstrated a negligible $(0.61 \%)$ decrease in the HbA1c level of the blood of the male rat. Decreases in HbA1c can occur in the several nondiabetic conditions, like hemolytic anemia, chronic blood loss or chronic renal failure of patient. ${ }^{23-26}$ There are some drug also involved in decreasing HbA1c level, like- acarbose, deferoxamine, diltiazem, enalapril, glipizide, glyburideetc. ${ }^{27}$ Whereas SMD demonstrated a negligible $(1.83 \%)$ increase in the
HbA1c level of the blood of the male rat, which was statistically not at all significant $(p=0.782)$. From this study we can say that, non-daibetic person can easily take both of the preparation but patient with high HbA1c (\%) level should be careful in taking SMD as it can elevate the HbA1c (\%) level a little bit. But MD is somehow beneficial for diabetic patient in some way as it decreases the glycated haemoglobin level in blood. Further study is needed for better understanding of the nature and features of those preparations.

\section{CONCLUSION}

Two herbo-mineral preparation (MD and SMD) were examined to find out the relation of chronic administration of those preparations and their effects on HbA1c (\%) level in rats. Between these preparation, MD demonstrated a negligible $(0.61 \%)$ decrease in the HbA1c level of the blood of the male rat, whereas SMD demonstrated an increased $(1.83 \%) \mathrm{HbA} 1 \mathrm{c}$ level of the blood of the male rat.

\section{ACKNOWLEDGMENTS}

The authors are thankful to Focused Research on Ayurvedic Medicine and Education (F.R.A.M.E) Laboratory, Department of Pharmacy, and all faculty members and the technical staffs of the Department of Pharmacy, Jahangirnagar University, for their kind cooperation. We would express our special thanks to $\mathrm{Mr}$. Shafiqul Islam for ensuring a constant supply of animals followed by proper maintenance and care of these animals during throughout the experimental period.

Funding: No funding sources

Conflict of interest: None declared 
Ethical approval: The study was approved by the Ethical Review Committee, Faculty of Life Sciences, Department of Pharmacy, Jahangirnagar University

\section{REFERENCES}

1. Khedekar SB, Prajapati PK, Galib R, Patgiri B. A scientific review of gold containingherbo-mineral preparation: Makaradhwaja. International Journal of Green Pharmacy (IJGP). 2016;9(4).

2. Kumar G, Srivastava A, Sharma SK, Rao TD, Gupta YK. Efficacy and safety evaluation of Ayurvedic treatment (Ashwagandha powder and Sidh Makardhwaj) in rheumatoid arthritis patients: a pilot prospective study. Indian Journal of Medical Research. 2015;141(1):100.

3. Kapoor RC. Some observations on the metal-based preparations in Indian systems of medicine. Indian journal of Traditional Knowledge. 2010;9(3):562-75.

4. Saggu S, Kumar RS, Singh VK, Govil JN. Stress management and herbal adaptogens. Chem Med Value. 2009;25:253-71.

5. Charde R, Sharma R, Patgiri BJ, Prajapati PK. Efficacy of Makaradhwaja on Madhumeha (Type2 diabetes): A review through ayurvedic studies. AJPCT; 2014;2:1470-9.

6. Kamath SU, Pemiah B, Sekar RK, Krishnaswamy S, Sethuraman S, Krishnan UM. Mercury-based traditional herbo-metallic preparations: a toxicological perspective. Archives of toxicology. 2012;86(6):831-8.

7. Carulli L, Rondinella S, Lombardini S, Canedi I, Loria P, Carulli N. Review article: diabetes, genetics and ethnicity. Alimentary pharmacology and therapeutics. 2005;22(2):16-9.

8. Weykamp C. HbA1c: a review of analytical and clinical aspects. Annals of laboratory medicine. 2013;33(6):393-400.

9. Alzahrani SH, Ajjan RA. Review article: Coagulation and fibrinolysis in diabetes. Diabetes and Vascular Disease Research. 2010;7(4):260-73.

10. Cavagnolli G, Comerlato J, Comerlato C, Renz P, Gross JL, Camargo JL. HbA1c measurement for the diagnosis of diabetes: is it enough? Diabetic Medicine. 2011;28(1):31-5.

11. Bennett CM, Guo M, Dharmage SC. HbAlc as a screening tool for detection of type 2 diabetes: a systematic review. Diabetic Medicine. 2007;24(4):333-43.

12. Procopiou M. HbA1c: review and recent developments. Revue Medicale Suisse. 2006;2(68):1473-4.

13. Ngiam KY, Lee WJ, Lee YC, Cheng A. Efficacy of metabolic surgery on $\mathrm{HbAlc}$ decrease in type 2 diabetes mellitus patients with BMI $<35 \mathrm{~kg} / \mathrm{m}^{2}$ : a review. Obesity surgery. 2014;24(1):148-58.

14. Karsdal MA, Krarup H, Sand JMB, Christensen PB, Gerstoft J, Leeming DJ, et al. Review article: The efficacy of biomarkers in chronic fibroproliferative diseases-early diagnosis and prognosis, with liver fibrosis as an exemplar. Alimentary pharmacology and therapeutics. 2014;40(3):233-49.

15. Levitan EB, Liu S, Stampfer MJ, Cook NR, Rexrode $\mathrm{KM}$, Ridker PM, et al. HbA1c measured in stored erythrocytes and mortality rate among middle-aged and older women. Diabetologia. 2008;51(2):267-75.

16. Khan HA, Sobki SH, Khan SA. Association between glycaemic control and serum lipids profile in type 2 diabetic patients: HbA1c predicts dyslipidaemia. Clinical and experimental medicine. 2007;7(1):24-9.

17. Selvin E, Coresh J, Jordahl J, Boland L, Steffes MW. Stability of haemoglobin A1c (HbA1c) measurements from frozen whole blood samples stored for over a decade. Diabetic medicine. 2005;22(12):1726-30.

18. Zander R, Lang W, Wolf HU. Alkaline haematin D575 , a new tool for the determination of haemoglobin as an alternative to the cyanhaemiglobin method, I. Description of the method. Clin Chim Acta. 1984;136(1):83-93.

19. Robers M, Van der Hulst FF, Fischer MA, Roos W, Salud CE, Eisenwiener HG, et al. Development of a rapid microparticle-enhanced turbidimetric immunoassay for plasma fatty acid-binding protein, an early marker of acute myocardial infarction. Clinical chemistry. 1998;44(7):1564-7.

20. Kumar G, Srivastava A, Sharma SK, Gupta YK. Safety evaluation of mercury based Ayurvedic formulation (Sidh Makardhwaj) on brain cerebrum, liver and kidney in rats. The Indian J of Med Res. 2014;139(4):610.

21. Vidyashankar S, Godavarthi A, Varma RS, Nandakumar KS. Water-soluble compounds in the herbal preparation Abana inhibit lipid biosynthesis and enhance cholesterol efflux in HepG2 cells. Canadian journal of physiology and pharmacology. 2010;88(4):456-64.

22. Rao BV, Srikumar BN, Rao BS. Herbal Remedies to Treat Anxiety Disorders. Anxiety; 2009:85.

23. Esposito K, Chiodini P, Bellastella G, Maiorino MI, Giugliano D. Proportion of patients at HbA1c target $<7 \%$ with eight classes of antidiabetic drugs in type 2 diabetes: systematic review of 218 randomized controlled trials with 78945 patients. Diabetes, Obesity and Metabolism. 2012;14(3):228-33.

24. Ngiam KY, Lee WJ, Lee YC, Cheng A. Efficacy of metabolic surgery on $\mathrm{HbAlc}$ decrease in type 2 diabetes mellitus patients with BMI $<35 \mathrm{~kg} / \mathrm{m}^{2}-\mathrm{a}$ review. Obesity surgery. 2014;24(1):148-58.

25. Silverberg DS, Wexler D, Blum M, Tchebiner JZ, Sheps D, Keren G, et al. The effect of correction of anaemia in diabetics and non-diabetics with severe resistant congestive heart failure and chronic renal failure by subcutaneous erythropoietin and intravenous iron. Nephrology Dialysis Transplantation. 2003;18(1):141-6.

26. Kohan DE, Fioretto P, Tang W, List JF. Long-term study of patients with type 2 diabetes and moderate renal impairment shows that dapagliflozin reduces weight and blood pressure but does not improve 
glycemic control. Kidney international. 2014;85(4):962-71.

27. Kang JG, Park CY. Anti-obesity drugs: a review about their effects and safety. Diabetes and Metabolism Journal. 2012;36(1):13-25.
Cite this article as: Sarker A, Biswas K, Chowdhury MI, Khan F, Sultana T, Afrin F, et al. Preclinical HbA1c level studies of makaradhwaja and siddha makaradhwaja after chronic administration to male Sprague-Dawley rats. Int J Basic Clin Pharmacol 2017;6:1249-53. 